\title{
Escribir sin palabras: la fotografía en Los fantasmas del masajista de Mario Bellatin*
}

Fecha de recepción: 10 de enero de 2018

Fecha de aprobación: 13 de mayo de 2019

\section{Resumen}

El presente artículo reflexiona en torno a los estímulos visuales presentes en la obra del escritor peruano/mexicano Mario Bellatin, específicamente en la incorporación directa de fotografías en Los fantasmas del masajista (2009). De este modo, se proponen cuatro ejes conceptuales que buscan ilustrar el sentido que tiene la inclusión de este elemento en el texto, así como el análisis del archivo fotográfico que, a simple vista, parecieran tener una evidente continuidad con el relato, pero que muchas veces más bien desconciertan y producen un efecto irrisorio. Finalmente, se plantea la interdisciplinariedad como un procedimiento que, lejos de favorecer la referencialidad en la obra, despierta una serie de dudas en el lector, efecto que se relaciona directamente con la propuesta artística de este escritor.

Palabras clave: Mario Bellatin, fotografía, interdisciplinariedad, procedimiento, ilusión referencial.

\section{Xiomara Silva Torres}

Profesora de español por la Universidad de Concepción. Actualmente, es candidata a Magíster en literaturas hispánicas de la misma casa de estudios. xsilva@udec.cl. (1) https:// orcid. org/0000-0002-9054-5594

* Este artículo de reflexión ha sido financiado por CONICYT. Beca magíster nacional. Chile/2018 22182093.

Citar: Silva Torres, X. (julio- diciembre de 2019). Escribir sin palabras: la fotografía en Los fantasmas del masajista de Mario Bellatin. La Palabra, (35), 29-39. (⿶) https://doi.org/10.19053/01218530.n35.2019.8846 


\section{Wordless Writing: Photography in Ma- rio Bellatin's Los fantasmas del masajista}

\section{Abstract}

This paper reflects on the visual stimuli present in the work of the Peruvian/Mexican writer Mario Bellatin, specifically in the direct incorporation of photographs in Los fantasmas del masajista (2009). In this way, four conceptual axes are proposed that seek to illustrate the meaning of the inclusion of this element in the text, as well as the analysis of the photographic archive that, at first sight, seem to have an obvious continuity with the story, but that many times rather puzzle and produce a derisory effect. Finally, interdisciplinarity is considered as a procedure that, far from favoring referentiality in the work, arouses a series of doubts in the reader, an effect that is directly related to the artistic proposal of this writer.

Keywords: Mario Bellatin, photography, interdisciplinarity, procedure, referential illusion. 
Desde su invención en el siglo XIX hasta la actualidad, la fotografía ha cautivado al ser humano, logrando modificar su percepción sobre el mundo que lo rodea. La posibilidad de capturar en forma exacta un momento en una imagen o de recortar un trozo de realidad para que perdure en el tiempo, había sido hasta entonces impensada. Así, desde la presentación del Daguerrotipo $^{1}$ en 1839 ante la Academia de Ciencias de París, la fotografía dio inicio al tiempo de la revolución tecnológica, industrialización, tecnificación y consumo, volviéndose cada vez más accesible e incorporándose a la vida diaria de las personas sin importar su condición socioeconómica ni su ubicación geográfica.

La fotografía, por tanto, se instala en el germen de nuestra cultura de masas y hoy en día forma parte de lo que Henry Jenkins (2006) denomina cultura de la convergencia. De este modo, no resulta extraño que este fenómeno haya sido objeto de estudio de variadas disciplinas e incluso que haya sido incorporado en otros tipos de creaciones artísticas.
En el caso de la literatura, la fotografía ha sido utilizada, a través del tiempo, básicamente de un modo ilustrativo. Sin embargo, la narrativa latinoamericana reciente hace uso de este recurso con una frecuencia cada vez mayor e incorpora en sus planteamientos una reflexión crítica respecto de las posibilidades interpretativas que se atribuyen a los estímulos visuales.

Mario Bellatin es, sin duda, uno de estos autores latinoamericanos cuya producción se encuentra plagada de la presencia de la visualidad. Su singular propuesta narrativa se basa en la experimentación literaria y la incorporación de recursos interdisciplinarios diversos, tal como señala Cote Botero (2014) en Mario Bellatin: El giro hacia el procedimiento y la literatura como proyecto:

La inclusión permanente de imágenes, el uso de procedimientos creativos que provienen del teatro o la fotografía, o la elección de soportes no tradicionales de impresión, contribuyen a la formulación en su obra de una visión de la escritura en sí misma, donde ésta es presentada como un procedimiento cuyos alcan- ces se extienden más allá del producto verbal (p. 2).

El escritor peruano-mexicano ha manifestado abiertamente sus intereses artísticos y su escritura se define, a grandes rasgos, por una plena conciencia de sí misma, así como por un afán por la ruptura de límites en su propia narración y en las distintas disciplinas artísticas. Una búsqueda que, sumada a sus experiencias educacionales y académicas $^{2}$, lo ha llevado a vincularse estrechamente con el mundo de las artes visuales, canalizando sus intereses en experiencias artísticas concretas, como es el caso de su participación en la Bienal documenta ${ }^{3} 13$ (2012).

Esta exposición, que se realiza cada cinco años en Kassel (Alemania), es uno de los eventos artísticos más importantes a nivel mundial y funciona como una suerte de centro neurálgico del mundo del arte contemporáneo y como un ejemplo de la importancia de la labor de dirección artística y curatorial. Bellatin es invitado a este evento como participante y curador, $\mathrm{y}$ es en esta instancia donde, además, presenta su proyecto Los cien mil libros de Bellatin,

\footnotetext{
Primer procedimiento fotográfico anunciado y difundido oficialmente por Nicéphore Niépce y Louis Daguerre el 19 de agosto de 1839. Mario Bellatin nace en Ciudad de México en 1960. Hijo de padres ítalo-peruanos, a los cuatro años se va junto con ellos a Perú, donde vive gran parte de su vida y estudia Teología durante dos años en el Seminario Santo Toribio de Mogrovejo y, posteriormente, Ciencias de la Comunicación en la Universidad de Lima. En 1987, fue becado en Cuba para estudiar Guion cinematográfico en la Escuela Internacional de Cine y Televisión de San Antonio de los Baños; y en el 2002, fue beneficiario de la beca Guggenheim. Bellatin fue, además, director del Área de Literatura y Humanidades de la Universidad del Claustro de Sor Juana y miembro del Sistema Nacional de Creadores de México de 1999 a 2005.

$3 \quad$ El nombre de este evento artístico se escribe con minúscula.
} 
una especie de propuesta editorial artesanal que tiene bastante de performance artística, pues busca redactar cien títulos propios con un tiraje inicial de mil libros cada uno. De acuerdo con el mismo Bellatin, esta propuesta se basa en un intento por romper con los criterios establecidos por la industria editorial, recuperando el sentido de intercambio que establece el autor con el lector, pues cada libro puede ser leído mediante préstamos, debiendo ser pagado solo si alguien desea poseerlo ${ }^{4}$.

Otra característica relevante en cuanto a este autor y al mundo artístico, es la utilización deliberada de su propia imagen como mecanismo expresivo; pues, como es sabido, Bellatin nace sin su brazo derecho, pero se ha encargado de transformar esta carencia en un hecho estético, por ejemplo, mediante una colección de extravagantes prótesis. De esta forma, su figura se ha convertido en un elemento simbólicamente productivo que abunda en su misma obra, puesto que las referencias en torno a su antebrazo faltante son numerosas y están presentes en varios de sus títulos.
Como vemos, la obra de Bellatin e incluso su personalidad artística, están llenas de elementos novedosos que buscan romper con lo tradicional. Es así como, en la obra de este escritor, es posible apreciar cada vez en mayor medida una incorporación decidida y consiente de la imagen en el texto, preocupación que ha evolucionado hasta la incorporación concreta de fotografías en sus textos. $\mathrm{Na}$ gaoka Shiki: una nariz de ficción (2001), Jacobo el mutante (2002), Perros héroes (2003) y Biografía ilustrada de Mishima (2009), son solo algunos ejemplos de este fenómeno.

Otra de las obras de Bellatin que se caracteriza por incorporar estímulos visuales, es Los fantasmas del masajista, novela corta $^{5}$ publicada en 2009 , que nos introduce en la historia de João, un masajista que trabaja en una clínica especializada en mutilados donde asiste el narrador, sujeto a quien el joven cuenta su historia: su madre había sido una talentosa declamadora, pero su éxito disminuía en forma progresiva. Ante esto, João decide regalarle una lora para que le haga compañía y la distraiga. Dicho animal, no muy querido al comienzo, se vuelve cada vez más cercano a la madre. Hasta que un día, una mala elección de contenido pone fin a su carrera y la mujer sufre una muerte repentina en extrañas condiciones. Es entonces cuando la lora comienza a demostrar ciertos rasgos de su difunta dueña, a tal nivel, que la gente asume que la madre habría resucitado en el animal.

En cuanto a las características generales de esta obra, encontramos una narración que remite a lo infantil, debido a que, a través de sus constantes repeticiones, pareciera conformarse un flujo discursivo continuo y sin fin. Además, tiene elementos autoficcionales, puesto que el narrador acude a una clínica especializada para tratar los dolores que le producía su falta de antebrazo derecho, situación que remite al propio Bellatin que tiene esta misma particularidad física.

\section{Los fantasmas del masajista incorpora un considerable ma- terial fotográfico, específica- mente un corpus de veintidós fotografías reunidas al final del volumen, con imágenes borro- sas, desenfocadas, con colores saturados; es decir, fotografías que, lejos de acercarse a lo}

\footnotetext{
$4 \quad$ Cabe destacar que este no es el único acercamiento de Bellatin a este desafío al sistema editorial. Para la publicación de su primera novela Mujeres de sal (1986), este autor encarga a una imprenta una especie de cupones de preventa, con los que las personas podrían adquirir la obra incluso antes de su publicación.

5 Establecemos esta clasificación considerando lo problemático que resulta definir la narrativa de este autor en cuanto a géneros literarios, puesto que, como señala la investigadora Florencia Garramuno (2015) en Arte inespecifico y mundos en común, la obra de Bellatin se caracteriza por «cuestionar de modo radical no solo la idea de un género específico al cual pertenecería el relato, sino sobre todo la idea de la literatura como institución con convenciones específicas que la separarían del resto de las artes» (p. 21).

$6 \quad$ Esta obra es publicada el mismo año que Biografia ilustrada de Mishima (2009), y ambas comparten rasgos intertextuales.
} 
profesional, tienen cierto aire aficionado. Otro elemento relevante es que cada una de estas imágenes se encuentra acompañada por un pie de foto. A simple vista, pareciera ser que la presencia de estas fotografías tendría un carácter referencial. No obstante, por medio de la lectura del pie de cada foto, nos damos cuenta de que, al parecer, la intención del autor al incorporar este elemento va más allá de la mera ilustración.

Para lograr la adecuada comprensión de estos estímulos visuales y su relevancia en la obra, es necesario adentrarnos en el mundo de lo visual y revisar las diversas propuestas que se han realizado acerca de la fotografía en la obra de Mario Bellatin. De este modo, hemos propuesto cuatro ejes conceptuales para comprender el sentido que tiene la inclusión de este elemento en el texto.

\section{La fotografía como huella o testimonio}

No cabe duda de que uno de los mayores atributos de la fotografía es la posibilidad de capturar un momento para que perdure en el tiempo, haciendo que la imagen permanezca como una especie de evidencia de realidad. En este sentido, podemos hablar de una concepción de la fotografía como una huella o un testimonio de algo que ya no está, una postura ampliamente abordada por Roland Barthes en su obra La cámara lúcida: notas sobre fotografía, publicada en 1980. En palabras de este autor:

La esencia de la fotografía es precisamente esta obstinación del referente en estar siempre ahí [...]. La fotografía es más que una prueba: no muestra tan sólo algo que ha sido, sino que también y ante todo demuestra que ha sido. En ella permanece de algún modo la intensidad del referente, de lo que fue y ya ha muerto (Barthes, 1989, p. 22).

Para Barthes, la fotografía, a diferencia de otras artes, se caracteriza por no poder fingir la realidad, puesto que el referente efectivamente "ha estado alli" (p. 21). Esta cualidad documental dota a la imagen fotográfica de cierta ilusión de referencialidad, pues al contemplarla nos remitimos a un elemento necesariamente real sin el cual la fotografía no existiría.

De este modo ocurre que, al enfrentarnos a las fotografías de Los fantasmas del masajista, nuestra experiencia nos lleve a asumir que algo de real deben tener, y se activa en nosotros la ilusión de referencialidad. Por ejemplo, la segunda fotografía «Espacio para las camillas individuales» pareciera estar remitiendo a la clínica a la cual hace referencia la narración, puesto que en ella vemos un espacio cerrado con varias mesas dispuestas una al lado de la otra y un par de personas que podrían ser masajistas. Todo esto, sumado a la imagen borrosa y en blanco y negro, nos lleva a considerar la posibilidad de que lo que se está mostrando tiene la función de ilustrar lo narrado. Lo mismo ocurre en el caso de la quinta fotografía «Madre de mi terapeuta favorito», que nos muestra una mujer apuntando a otra de edad madura, que podría coincidir con la que es descrita en el relato.

Sin embargo, a medida que avanza el dossier fotográfico, nos damos cuenta de que la mayoría de las imágenes presenta un pie de foto que, lejos de señalar objetivamente lo que se muestra en la imagen, más bien desconcierta y produce un efecto irrisorio. Tal es el caso de la tercera fotografía «Lugar vacío dejado por la pierna mutilada», que de acuerdo con el texto haría referencia a un elemento corporal, pero la imagen presenta una especie de construcción con un hueco en medio.

Esta ilusión de referencialidad que genera la inclusión de fotografías, se produce también al nivel de la textualidad mediante otro de los recursos claves de la narrativa bellatiniana: la autoficción. La inclusión de datos y hechos verdaderos de la vida del autor, en este caso, la particularidad física del protagonista, nos remite necesariamente a la falta de antebrazo de Mario Be- 
llatin. Por lo tanto, al incorporar elementos "reales", se produce un juego entre lo real y lo ficticio en la narración, tanto verbal como visual. Tal como señala Florence Olivier (2016) en De algunos usos de la fotografía en la literatura hispanoamericana contemporánea:

Tradicionalmente, la imagen fotográfica parecería certificar que en otra parte y en otro tiempo tuvieron presencia y existencia material aquellos cuerpos, rostros y objetos que registra. Si bien casi todas las obras leídas aquí interrogan los relatos biográficos o autobiográficos -convencionalmente asociados con lo real- y apuntalan la ficción, prolongándola, mediante los usos diversos y, en ocasiones, verdaderamente narrativos, literarios, al cabo, que hacen de la fotografía, es de notarse que con estos fines la foto, discreta o paródicamente desviada de su manejo como certificado de realidad, cualquiera que haya podido ser su eventual y original índole documental, convierte lo referencial real en referencia ficticia (p. 446).

Por tanto, nos encontramos ante un doble uso del recurso fotográfico, en el que algunas fotografías se muestran como referenciales, mientras que otras no tienen nada que ver con lo planteado en el texto, es más, difícilmente podríamos considerarlas ilustrativas. Situación que nos lleva a considerar una segunda propuesta conceptual acerca de la función de la fotografía.

\section{La fotografía como defecto o deformación de la realidad}

Desde sus inicios, la fotografía se sitúa en una posición ambivalente, puesto que, por un lado, se la considera como un testimonio por su capacidad de reproducir y documentar la realidad; y, por otro, se reconoce que no es completamente objetiva, pues también tiene un potencial de distorsión de aquello que representa. Este «haber estado allí» de las cosas que planteaba Barthes, funciona en Los fantasmas del masajista (2009), como una ilusión referencial que el lector debe percibir como un recurso del escritor para deformar ${ }^{7}$ la realidad planteada en su narración.

Uno de los estudios que aborda este tema es Mario Bellatin: imágenes literarias. En este texto, Walker (2009) señala que, en muchas de sus obras, Bellatin juega con los límites entre realidad y ficción, buscando alterar las expectativas que el lector tiene acerca de la fotografía en el texto, pues las fotos y fragmentos aquí:

Redoblan el carácter ilusorio del referente, y construyen así sus propias normas de verosimilitud. La fotografía presentada como un defecto o alteración de lo que exhibe, se articula con una escritura que opera sobre los mismos territorios [...]. Allí donde se erige algo como un supuesto límite de lo literario -la imagen fotográfica- se expone más bien la manera en donde de hecho trabaja la literatura de Bellatin (p. 5).

Como vemos, la obra de Mario Bellatin se caracteriza por valerse de este carácter ilusorio del referente para validar las posibilidades especulares que confieren las fotografías al final del relato. Lo que nos lleva a preguntarnos ¿de qué manera el lector llega a la conclusión de que lo que está viendo no es verdadero?, ¿cómo se percibe este quiebre entre el relato verbal y el visual?

La respuesta nos lleva a reflexionar en torno al pie de foto presente en cada imagen. De acuerdo con Sontag (2017), el atractivo de la fotografía radica en aquello que no nos dice, pues este silencio constituye una provocación. Sin embargo, algunas veces las fotografías van acompañadas de un texto que pretende explicar su contenido. Para ella, "la voz ausente es el pie, y se espera que diga la verdad. Pero aun un pie absolutamente preciso es solo una interpreta-

\footnotetext{
$7 \quad$ Esta idea de deformación es, además, una constante temática en la obra de Mario Bellatin, basta con recordar que la historia de Los fantasmas del masajista (2009) se desarrolla en una clínica para mutilados.
} 
ción, necesariamente limitada de la fotografía que acompaña" (p. 111).

Si pensamos en el texto de Bellatin, nos damos cuenta de que en muchos casos el pie de foto de cada imagen resulta absurdo, puesto que lo descrito verbalmente excede las posibilidades físicas que la imagen denota. Por ejemplo, la sexta fotografía nos muestra un primer plano recortado de un sujeto joven con lentes de sol, la imagen es borrosa y está en blanco y negro, el pie de foto señala "Joven que asesinó a su tatarabuela dentro de una canción popular", o bien, la fotografía número diecisiete muestra una imagen a color de un hombre de espaldas y el pie describe "Espalda de Joäo dentro del sueño". Por tanto, en estas imágenes el texto genera un efecto de extrañeza, pues remiten a elementos imposibles de capturar, incluso oníricos.

En aquellos casos en que el pie de foto es concordante y coherente con su imagen, al remitirlo al texto narrativo es inevitable pensar en lo inútil que resulta añadir este tipo de información. Por ejemplo, en la décima fotografía se muestra una imagen muy desenfocada, en la que se pueden apreciar unos pequeños animales de juguete. Su pie de foto señala "Juguete para loros". Si bien es cierto, podrían serlo, resulta absurdo incorporar este elemento. Lo mismo ocurre en el caso de la fotografía catorce, donde se muestra a una mujer y el texto señala "Presidenta de la Sociedad de Declamadoras", puesta que esta figura jamás se menciona en la novela y no tendría ninguna relevancia incorporarla en una fotografía.

Tal como lo explica Sontag, nos encontramos ante una situación en que el lector se ve interpelado por estos elementos confusos. "Las fotografías en sí mismas no explican nada, son inagotables invitaciones a la deducción, la especulación y la fantasía" (p. 32). Por lo tanto, la inclusión del elemento fotográfico en esta novela de Bellatin más que ilustrar verídicamente como supuestamente intenta, nos hace darnos cuenta de que se trata de un juego entre ambos códigos, el verbal y el visual, puesto que lo que uno estaría afirmando, el otro lo desmiente.

\section{La fotografía como recorte o amputación}

Otra de las concepciones clásicas acerca de la fotografía es que consiste en un trozo del mundo, un recorte de la realidad, que estaría dado por los límites naturales de la imagen: el encuadre. Los bordes de la fotografía son los que señalan el corte, la distancia entre la realidad y una imagen de ella. En este sentido, si pensamos en Los fantasmas del masajista, es posible percatarnos de algunos elementos relevantes respecto a la disposición de lo visual en el texto.

En primer lugar, encontramos que, a nivel de la narración, el texto en cada página está dispuesto a modo de bloque, con bastante aire del borde de la página, sin justificado y con un uso limitado de la puntuación, como si se tratara de un flujo constante, pero recortado por el espacio que lo limita ${ }^{8}$.

En segundo lugar, con respecto a lo visual, en el texto se produce un corte abrupto en la discursividad para dar lugar al dossier de fotografías. Todas ellas están dispuestas de manera ordenada, una en cada página, veintidós en total y con su pie de foto respectivo. Llama la atención la especial disposición de estos elementos en la obra, ya que fotografía y texto parecieran estar enmarcados al mismo nivel, en bloques de igual tamaño. Además, el hecho de que la fotografía no sea incorporada dentro del mismo texto, sino que, mediante un corte visual, confiere a ambos códigos una especie de igualdad, al parecer no hay una competencia entre la relevancia de cada uno, sino que su incor-

8 Cabe destacar que, en función de este estudio, se trabajó con la edición de 2009 de la editorial Eterna Cadencia en que es posible apreciar estos detalles visuales, situación que no ocurre, por ejemplo, en las Obras Completas. 
poración tendría el mismo grado de validez.

Este cuestionamiento acerca del lugar que ocupa la fotografía en la narración, forma parte del extenso debate que ha tenido lugar entre los distintos críticos de la obra de Bellatin. Por un lado, existen algunos que defienden la equivalencia de ambas formas, como la investigadora Valeria de los Ríos (2015), que postula en Analogías: Fotografía y literatura en Mario Bellatin, que esta relación entre literatura y fotografía se puede explicar mediante la noción de analogía, puesto que ambas funcionan de un modo similar, sin preponderancia de una sobre la otra, desestabilizando la noción de sujeto y de representación. De este modo, explica que "La relación entre literatura y fotografía [...] está íntimamente emparentada con la noción de analogía: la analogía entre escritura alfabética y escritura de luz, la analogía entre biografía y autobiografía, entre objetos y circunstancias" (p. 9), por lo que abandona la intención de referencia.

Por otro lado, encontramos propuestas como la de Alan Pauls (2005), quien realiza una arriesgada afirmación respecto de la relación interdisciplinaria y señala que en la narrativa de Bellatin "lo escrito se delata como insuficiente y llama a la imagen; la imagen nunca alcanza y añora lo escrito" (Pauls, 2005).
Finalmente, existen otros que, más allá de determinar el grado de importancia de la fotografía en el texto o la preponderancia de uno sobre otro, eligen valorar la interdisciplinariedad como un proceso creativo en sí mismo. Tal es el caso de investigadores como Carlos Leonel Cherri (2015), quien en Formas de la imagen en Mario Bellatin: una pregunta por lo sensible, señala que:

La irrupción de las fotografías en los libros de Bellatin coincide no sólo con la intensificación de su "falsa retórica" que leímos en términos de exotismo, sino también con una preocupación tanto por el estatuto literario como por la imagen de autor. En ese proceso, es crucial al respecto la exploración de la relación entre imagen y literatura. De ese modo, las intervenciones y proyectos artísticos de Bellatin funcionan, al igual que sus libros, como una suerte de laboratorios instalados a la sazón de dar rienda suelta a un experimento (p. 7).

En este sentido, coincidimos con el autor en que resulta fundamental reconocer la intención de Mario Bellatin al recurrir a este tipo de archivos, así como valorar la experimentación en la propia escritura. Tal como ha señalado el mismo Bellatin en sus entrevistas, existiría en él una constante búsqueda por llevar su escritura al límite (Bellatin, 1992). Por este motivo, más que explicar la relación en- tre fotografía y literatura como una analogía o bien como una pugna entre ambas formas, pretendemos ilustrar el modo en que esta relación se articula en el texto, así como las diferentes formas en que puede entenderse este recurso interdisciplinario, pues luego de todo análisis de los recursos de representación, siempre volvemos a la misma escritura. Como señala el propio Bellatin (citado en Cherri y Cuartas, 2017):

\begin{abstract}
Más que una relación con los archivos se trata de la relación con la escritura. Entre el hecho de escribir como acto físico de producir la palabra, y hacer literatura u organizar ese material en forma de libro. Mi proceso normal de creación está formado por dos etapas. En principio consiste en crear una serie de material de escritura sin finalidad determinada, es decir, determinado libro o historia; y después viene el proceso de armar esa escritura para darle una forma que le permita ser transmitida, y así convertirse en un sistema de flujo (p. 75).
\end{abstract}

Esta escritura como un procedimiento, como un hecho físico de recortar y armar un objeto, también es muy relevante en Los fantasmas del masajista a nivel temático, puesto que el espacio en que transcurren los hechos es "una clínica especializada en personas que han perdido o están por perder algún miembro" (Bellatin, 2009, p. 4). Por tanto, el factor del recorte y de lo fal- 
tante está siempre presente en la narración.

Tal es el caso de uno de los personajes que el narrador conoce en este centro, una mujer a quien le habían amputado una pierna, pero que seguía sintiendo un dolor persistente en esta pierna fantasma. Lo mismo ocurre si pensamos en el masajista Joäo, quien luego de perder a su madre sufre una especie de amputación simbólica que lo atormenta. En efecto, se trata de un ser fantasmal que está presente en la vida de los personajes, del mismo modo en que ocurría en la propuesta de Barthes, donde el Spectrum era el objeto fotografiado que remitía a un momento pasado y a una ausencia en el presente.

\section{La fotografía como copia o duplicación}

Para finalizar, la última de las propuestas conceptuales para comprender el fenómeno de lo visual en el texto, es entender la fotografía como duplicación, que implica una captura de la realidad que nunca será esta misma realidad. Para Barthes (1989), "la fotografía repite mecánicamente lo que nunca más podrá repetirse existencialmente" (p. 29).

Este sentido de duplicación es muy relevante en la obra, ya que, a nivel temático, la repetición es una constante, ya sea en el oficio de la madre como de- clamadora, en la máquina contestadora que había en la casa del protagonista, o bien, en la lora que Joäo le regala a su madre. Como sabemos este animal al comienzo no hablaba, pero luego de la muerte de la madre, comienza a adquirir algunos rasgos humanos:

Parece que desde entonces el animal se desató, pues repitió esa misma noche, casi ya al amanecer, las estrofas completas de la canción de Chico Buarque. Hizo una serie de combinaciones con las frases, incluso mayor en cantidad de las que contiene el tema original (Bellatin, 2009, p. 67).

Además, luego de la muerte de la madre, esta lora adquiere sus cualidades representativas, es más, para la gente cercana, la mujer habría resucitado en el animal, situación que asimilan con mucha facilidad. Por tanto, nos encontramos con una pérdida y una duplicación de lo que algo fue un día. Lo mismo ocurre en la fotografía, pues por más que se quiera representar la realidad, se trata de un momento irrepetible.

La idea de duplicación es constante en la obra de Mario Bellatin, tal como lo explica Cote Botero (2014), en ella hay un "sistema de recurrencias [...] que en términos muy generales podría dividirse en: circuito de formas auto-referenciales, una comunidad de temas que supo- nen la construcción de un sistema de insistencias y el de la copia" (p. 22).

Resulta interesante destacar, no obstante, que la duplicación no funciona solamente en la narrativa de Bellatin, sino que se encuentra presente en las diversas instalaciones que el escritor ha realizado. Como es el caso del proyecto del Congreso de dobles (2003), en el que este autor organiza un falso congreso de escritores mexicanos en una galería de París. Aquí, presenta a cuatro personas que han aprendido de memoria los discursos de escritores, como Salvador Elizondo, Sergio Pitol, Margo Glanz y José Agustín; con el objetivo de trasladar "al lugar del evento sólo las ideas de estos creadores, para constatar qué ocurría con los textos una vez que estuvieran huérfanos de sus autores" (Neyra, 2006, párr. 5). De este modo, esta acción de Bellatin genera una serie de críticas y quejas por parte de académicos europeos que habían viajado solo para estar junto a los escritores mexicanos. Este tipo de actividades, que bien podemos denominar performance, ponen en discusión la posibilidad de ubicar a la literatura en un espacio contiguo al de las artes visuales.

Como vemos, nos encontramos ante una propuesta escritural que se basa en la repetición de tópicos, situaciones y personajes. El mismo Bellatin ha 
manifestado abiertamente su intención de que su obra esté contenida en un mismo libro, por tanto, hay una intención de continuidad entre los textos. No es de extrañar, entonces, que ocurra una situación similar en los recursos fotográficos que emplea.

En Bellatin, encontramos una migración de fotografías, que contribuyen a fortalecer el carácter ambiguo y anti referencial de las imágenes en sus textos. Por ejemplo, el caso de la fotografía "Habitación de la madre de Joäo" se encuentra presente también en otra novela llamada Las dos Fridas, donde el pie de foto se cambia a "Vista de la habitación de Frida Kahlo", situación que se repite en muchas de sus obras.
A modo de síntesis, si partimos de la idea barthesiana de que el orden fundador de la fotografía es la referencia, ya que en esta nunca se puede negar que "la cosa ha estado allí", en la obra de Bellatin nos encontramos con algunos problemas puesto que, si bien es cierto, las fotografías que incorpora podrían conservar ciertos elementos que provienen directamente de su referente, necesitan, sin embargo, ser interpretadas y valoradas. Bellatin nos señala que, como todo lenguaje, la fotografía no es neutra, aunque a veces lo parezca.

En Los fantasmas del masajis$t a$, la relación entre imagen y texto, lejos de fijar el sentido de la imagen, genera un efecto contradictorio. El mismo Bellatin señala que este recurso se debe a que "quería enrarecer las cosas, para que realmente surtieran efecto. Uno está esperando una forma determinada para un tema, pero si el tema está y la forma es totalmente inesperada, se crea esa cosa que hace que leas doblemente" (Rodríguez, 2006, p. 68).

Al concebir la escritura como un hecho físico de producir la palabra, como una constante experimentación de formas $\mathrm{y}$ recursos, la fotografía adquiere una función desmitificadora que le sirve al autor como un dispositivo que condensa sus preocupaciones sobre la literatura y el lenguaje. Este procedimiento resulta el medio ideal al presentar un innegable grado de realidad, como señala Barthes (1989) "esto ha sido" (p. 21) que, sin embargo, lleva al lector a preguntarse ¿esto ha sido?

\section{Referencias}

Barthes, R. (1980). El mensaje fotográfico (1961), La retórica de la imagen (1964) y El tercer sentido (1970) en Lo obvio y lo obtuso. Imágenes, gestos, voces. Barcelona: Paidós.

Barthes, R. (1989). La cámara lúcida. (J. Sala-Sanahuja, Trad.). Barcelona: Paidós.

Bellatin, M. (1992). Efecto invernadero: un nuevo estilo de la novela en Mario Bellatin (Entrevistador J. Arévalo). El comercial, México. 
Bellatin, M. (2009). Los fantasmas del masajista. Buenos Aires: Eterna Cadencia.

Cote Botero, A. (2014). Mario Bellatin: el giro hacia el procedimiento y la literatura como proyecto. Pennsylvania: University of Pennsylvania. Recuperado de https://repository.upenn.edu/cgi/ viewcontent.cgi?referer=https:/www.google.com/\&httpsredir=1\&article=3056\&context=edissertations

Cherri, L. (2015). Formas de la imagen en Mario Bellatin: una pregunta por lo sensible. IX Congreso Orbis Tertius de Teoría y Crítica Literaria. Recuperado de http://sedici.unlp.edu.ar/bitstream/ handle/10915/63027/Documento_completo__.pdf-PDFA.pdf? sequence=1\&isAllowed=y

Cherri, L. \& Cuartas, J. (2017). El nombre del universo: primeros apuntes sobre el Cuaderno de Teología de Mario Bellatin. Manuscrítica. Revista de crítica genética, (33), 73-89. Recuperado de http:// www.revistas.fflch.usp.br/manuscritica/article/view/2864

De los Ríos, V. (2015). Analogías: Fotografía y literatura en Mario Bellatin. En Trans, 19. Recuperado de https://journals.openedition.org/trans/1089

García, M. (2017). Textoplasma: La imagen como fantasma de la escritura en la obra de Mario Bellatin. Tropelías. Revista de la literatura y literatura comparada, (27), 56-66. DOI: https://doi. org/10.26754/ojs_tropelias/tropelias.2017271539

Jenkins, H. (2006). La Cultura de la Convergencia de los Medios de Comunicación. Nueva York: Paidós Ibérica, S.A.

López, F. (2015). Mario Bellatin, el cuadernillo de las cosas difíciles de explicar. Alicante: Universidad de Alicante.

Neyra, E. (2006). Hay como una búsqueda constante de escribir sin escribir, de resaltar los vacíos, las omisiones, antes que las presencias. (Entrevista a Mario Bellatin). Chile: Proyecto Patrimonio. Recuperado de http://www.letras.mysite.com/mb240606.htm

Olivier, F. (2016). De algunos usos de la fotografía en la literatura hispanoamericana contemporánea. Cuadernos de Literatura, 20(40), 430-448. DOI: https://doi.org/10.11144/Javeriana.cl20-40.aflh

Pauls, A. (2005). El problema Bellatin. El Interpretador.net, (20). Recuperado de http://www.elinterpretador.net/20AlanPauls-ElProblemaBellatin.html

Rodríguez, F. (2006). Entrevistas. Mario Bellatin. Hispanoamérica, 35(103).

Sontag, S. (2017). Sobre la fotografía. (C. Gardini, Trad.). Buenos Aires: Alfaguara.

Walker, C. (2009). Mario Bellatin: imágenes literarias. Actas del II Congreso Internacional Cuestiones críticas: Rosario. Recuperado de http://www.celarg.org/int/arch_publi/walker_acta.pdf 